\title{
ANALISIS DAMPAK ALIH FUNGSI LAHAN PERKEBUNAN TERHADAP PENDAPATAN PETANI DI KECAMATAN SERUWAY KABUPATEN ACEH TAMIANG
}

\author{
Muslimah $^{1}$, Megawati $^{2}$ \\ ${ }^{I}$ Dosen Fakultas Pertanian Universitas Samudra \\ ${ }^{2}$ Mahasiswa Program Studi Agribisnis Fakultas Pertanian Universitas Samudra
}

\begin{abstract}
Abstrak
Penelitian ini bertujuan untuk menganalisis dampak alih fungsi lahan pertanian perkebunan terhadap pendapatan penduduk. Penelitian ini dilakukan dengan mengunakan metode survey. Objek dalam penelitian ini hanya dibatasi pada petani yang melakukan kegiatan alih fungsi lahan perkebunan sawit ke jeruk manis yang ada dalam wilayah kecamatan Seruway Kabupaten Aceh Tamiang. Ruang lingkup penelitian ini meliputi luas lahan garapan, penggunaan tenaga kerja, biaya produksi, produksi dan pendapatan. Hasil penelitian Analisis Chi-Square diperoleh sebagai berikut: $X^{2}$ hitung $=9,95$. Sedangkan harga $X^{2}$ tabel pada taraf kepercayaan $95 \%(\alpha=0,05)$ dan derajat bebas $(d b)=4$ diperoleh nilai sebesar 9,488 , hal ini menunjukkan bahwa $X^{2}$ hitung $>X^{2}$ tabel. Dapat dilihat bahwa perbandingan antara nilai $X^{2}$ hitung sangat berbeda dengan nilai $X^{2}$ tabel. Dengan demikian dapat dinyatakan bahwa terdapat pengaruh pendapatan petani yang signifikan akibat alih fungsi lahan perkebunan kelapa sawit ke jeruk manis di Kecamatan Seruway Kabupaten Aceh Tamiang. Jadi hipotesis yang menyatakan alih fungsi lahan perkebunan berdampak terhadap pendapatan petani di Kecamatan Seruway Kabupaten Aceh Taming diterima (terima Ha tolak Ho)
\end{abstract}

Kata kunci: Alih fungsi lahan,perkebunan sawit,perkebunan jeruk manis

\section{PENDAHULUAN}

Kabupaten Aceh Tamiang yang berada dalam Propinsi Aceh merupakan suatu daerah yang menjanjikan untuk meningkatkan usaha-usaha pertanian. Ini dapat dilihat dengan adanya program pemerintah untuk meningkatkan pembangunan pertanian di seluruh daerah Aceh termasuk perkebunan. Alih fungsi lahan perkebunan merupakan salah satu fenomena yang cukup banyak terjadi pada saat ini dalam pemanfaatan lahan. Hal ini disebabkan seiring dengan pertambahan penduduk dan kegiatan pembangunan sehingga mengakibatkan semakin tinggi dan bertambahnya akan permintaan dan kebutuhan terhadap lahan yang dipergunakan untuk menyelenggarakan kegiatan, baik dari sektor pertanian maupun dari sektor non pertanian. Hal ini sesuai dengan perinsip ekonomi, bahwa pengguna selalu akan memaksimalkan penggunaan lahannya.

Tindakan alih fungsi lahan perkebunan sebenarnya telah terjadi sejak adanya manusia di dunia (termasuk nenek moyang bangsa Indonesia) dengan mengenal bermacam-macam sesuatu (obyek) yang dikehendaki demi mempertahankan dan memperoleh kepuasan hidupnya seperti pangan, sandang, papan dan sebagainya. Namun kebutuhan itu terus bertambah baik jenis, corak, jumlah, maupun kualitasnya seiring dengan bertambahnya populasi manusia. Oleh karenanya dengan kebutuhan ini berarti menghendaki lebih banyak lagi lahan perkebunan yang perlu dirubah baik fungsi, pengelolaan sekaligus menyangkut kepemilikannya. Alih fungsi lahan perkebunan dapat menyangkut suatu tindakan untuk mengoptimalkan (meningkatkan fungsi dan mengefektifkan) lahan perkebunan menjadi lahan sejenis dan atau merubah/mengganti fungsi lahan perkebunan menjadi lahan jenis lain (lahan non pertanian), bahkan ada yang langsung / sengaja atau tidak langsung dapat merusak kondisi lahan tersebut, disamping dapat menjadi sumber ketegangan/konflik baik antar individu/kelompok/ organisasi bahkan antar Negara (Isa, 2006).

Alih fungsi lahan perkebunan di Aceh terjadi salah satunya di Kabupaten Aceh Tamiang, yang cenderung mengalami peningkatan setiap tahunnya, hal ini dapat dilihat dari data yang menunjukkan berkurangnya luas lahan perkebunan sawit pada tahun 2010 seluas 35.993 ha dan tahun 2015 seluas $32.845 \mathrm{Ha}$, hal ini menunjukkan dalam kurun waktu 5 tahun, telah terjadi alih fungsi lahan perkebunan sawit mencapai $3.148 \mathrm{Ha}$ 
(Dinas Pertanian Tanaman Pangan Kabupaten Aceh Tamiang, 2017).

Tabel 1. Luas Penggunaan Lahan Sebelum dan Setelah Melakukan Alih Fungsi Lahan Perkebunan Di Kecamatan Seruway Tahun 2016

\begin{tabular}{|c|l|r|r|r|r|}
\hline \multirow{2}{*}{ No } & \multirow{2}{*}{ Nama Desa } & \multicolumn{4}{|c|}{ Jenis Penggunaan Lahan (Ha) } \\
\cline { 3 - 6 } & & \multicolumn{2}{|c|}{ Sebelum Alih Fungsi Lahan } & \multicolumn{2}{|c|}{ Setelah Alih Fungsi Lahan } \\
\cline { 3 - 6 } & & Kebun Sawit & Jeruk Manis & Kebun Sawit & Jeruk Manis \\
\hline 1 & S. Kuruk I & 75 & 95 & 70 & 100 \\
2 & S. Kuruk II & 50 & 26 & 30 & 46 \\
3 & S. Kuruk III & 50 & 7 & 42 & 15 \\
4 & Binjai & 10 & 1 & 5 & 6 \\
5 & Pasar Baru & 35 & 1 & 10 & 26 \\
6 & Tangsi Lama & 115 & 7 & 90 & 32 \\
7 & Lubuk Damar & 38 & 3 & 20 & 21 \\
8 & Gedung Biara & 12 & 7 & 10 & 9 \\
9 & Paya Udang & 57 & 4 & 30 & 23 \\
10 & Gelung & 8 & 2 & 512 & 283 \\
\hline
\end{tabular}

Sumber: BPP Kecamatan Seruway, 2017

Sebagian besar perubahan lahan perkebunan dialihfungsikan menjadi perkebunan jeruk manis. Hal ini dikarenakan petani menganggap kegiatan perkebunan jeruk manis lebih menjanjikan jika dibandingkan dengan tanaman perkebunan lainnya karena dalam budidayanya tanaman jeruk manis termasuk lebih mudah dan tidak membutuhkan biaya yang besar.

\section{TINJAUAN PUSTAKA \\ Kelapa Sawit}

Faktor utama yang mempengaruhi produktivitas hasil perkebunan seperti kelapa sawit yaitu penggunaan bibit yang berkualitas, seperti yang diungkapkan Pahan (2006) bahwa investasi yang sebenarnya bagi perkebunan komersial beradapada bahan tanaman (benih/bibit) yang akan ditanam, karena merupakan sumber keuntungan pada perusahaan kelak.

Kelapa sawit merupakan tanaman perkebunan penting penghasil minyak makanan, minyak industri, maupun bahan bakar nabati (biodiesel). Indonesia penghasil minyak kelapa sawit kedua dunia setelah Malaysia. Sejalan dengan perluasan areal tanam, produksi meningkat dengan laju $9,4 \%$ per tahun(Harahap, 2011).

\section{Jeruk Manis}

Jeruk manis dengan nama latin Citrus aurantium adalah tanaman holtikultura yang populer di masyarakat. Tanaman jeruk manis tersebar luas karena pembudidayaannya tidak terlalu sulit, yang dibutuhkan hanyalah tanah dengan tingkat kesuburan dan kandungan air yang cukup. Biasanya, tanaman jeruk manis diperbanyak dengan cara dicangkok atau okulasi, namun bisa juga melalui bijinya.

Kandungan senyawa dalam jeruk manis yang kaya vitamin $\mathrm{C}$, potassium, dan folid acid, dapat berfungsi untuk menghambat sel-sel kanker. Selain kaya serat, buah berwarna kuning ini juga mengandung hesperidin yang mampu menurunkan resiko penyakit jantung, mencegah kolesterol, serta menurunkan tekanan darah. Dalam satu buah jeruk manis ukuran sedang terdapat 16 gram karbohidrat yang mengandung 70 kalori. Karbohidrat ini penting sebagai sumber energi tubuh, terutama untuk otak. Nilai serat dalam sebuah jeruk manis setara dengan 12 persen yang dibutuhkan per 
hari. Fungsi serat jelas sangat penting antara lain membantu proses pencernaan. Serat dalam jeruk manis bisa membantu menurunkan kadar kolesterol dalam darah dan juga menurunkan resiko penyakit jantung.

\section{Alih Fungsi Lahan}

Pangan merupakan kebutuhan mendasar bagi manusia untuk dapat mempertahankan hidup. Oleh karena itu kecukupan pangan bagi setiap orang pada setiap waktu merupakan hak azasi yang layak dipenuhi. Berdasarkan kenyataan tersebut masalah pemenuhan kebutuhan pangan bagi seluruh penduduk setiap saat di suatu wilayah menjadi sasaran utama kebijakan pangan bagi pemerintahan suatu negara.

Dalam UU RI Nomor 10Tahun 2012 tentang pangan, pangan didefinisikan sebagai segala sesuatu yang berasal dari sumber hayati dan air, baik yang diolah maupun tidak diolah yang diperuntukan sebagai makanan atau minuman bagi konsumsi manusia, termasuk bahan tambahan pangan, bahan baku pangan, dan bahan lain yang digunakan dalam proses penyiapan, pengolahan, dan atau pembuatan makanan atau minuman. Sedangkan Ketahanan Pangan adalah suatu kondisi terpenuhinya pangan bagi rumah tangga yang tercermin dari tersedianya pangan secara cukup, baik jumlah maupun mutu, aman, merata dan terjangkau.

Ketidakseimbangan pertumbuhan

permintaan dan pertumbuhan kapasitas produksi nasional tersebut mengakibatkan adanya kecenderungan meningkatnya penyediaan pangan nasional yang berasal dari impor. Ketergantungan terhadap pangan impor ini terkait dengan upaya mewujudkan stabilitas penyediaan pangan nasional. Salah satu usaha dalam mewujudkan stabilitas pangan dan menambah pendapatan maka petani melakukan alih fungsi lahan.

Alih fungsi lahan atau lazimnya disebut sebagai konversi lahan adalah perubahan fungsi sebagian atau seluruh kawasan lahan dari fungsinya semula (seperti yang direncanakan) menjadi fungsi lain yang menjadi dampak negatif (masalah) terhadap lingkungan dan potensi lahan itu sendiri.

Faktor- faktor Yang Mempengaruhi Alih Fungsi Lahan

Faktor-faktor yang menentukan alih fungsi lahan pertanian dikelompokkan menjadi tiga, yaitu faktor ekonomi misalnya pendapatan, faktor sosial misalnya pendidikan dan pengalaman serta peraturan pertanahan yang ada (Ilham, 2005), lebih lanjut Isa (2006), menyatakan faktor yang mendorong konversi lahan pertanian adalah :

a.Pertumbuhan penduduk,

b. Kebutuhan lahan untuk kegiatan non pertanian,

c.Nilai land rent yang lebih tinggi pada aktivitas pertanian non pangan,

d. Sosial budaya,

e.Degradasi lingkungan,

f.Otonomi daerah yang mengutamakan pembangunan pada sektor yang lebih menguntungkan untuk peningkatan Pendapatan Daerah, dan

g. Lemahnya sistem perundangundangan dan penegakan hukun dari peraturan yang ada. Land rent atau rente lahan merupakan salah satu konsep yang digunakan untuk menentukan nilai lahan.

Pengalaman petani merupakan suatu pengetahuan petani yang diperoleh melalui rutinitas kegiatannya sehari-hari atau peristiwa yang pernah dialaminya. Pengalaman yang dimiliki merupakan salah satu faktor yang dapat membantu memecahkan masalah yang dihadapi dalam usahataninya. Hal ini sesuai dengan pendapat Liliweri (2007: 33).

Pengalaman merupakan faktor personal yang berpengaruh terhadap perilaku seseorang. Dalam mempersepsi terhadap sesuatu obyek biasanya didasarkan atas pengalamannya. Jika petani mempunyai pengalaman yang relatif berhasil dalam mengusahakan usahataninya, biasanya mempunyai pengetahuan, sikap dan keterampilan yang lebih baik, dibandingkan dengan petani yang kurang berpengalaman. Namun jika petani selalu mengalami kegagalan dalam mengusahakan usahatani tertentu, maka dapat menimbulkan rasa enggan untuk mengusahakan usahatani tersebut. Dan bila ia harus melaksanakan usahatani tersebut karena ada sesuatu tekanan, maka dalam mengusahakannya cenderung seadanya. Dengan demikian pengalaman petani dalam berusahatani merupakan salah satu faktor yang mempengaruhi tingkat adopsi inovasi pertanian (Syafaruddin, 2009: 21).

\section{Pendapatan}


Analisis pendapatan mempunyai dua tujuan bersama yaitu menggambarkan keadaan sekarang dari suatu kejadian usaha dan menggambarkan keadaan yang akan datang dari suatu perencanaan atau tindakan. Analisis pendapatan membutuhkan dua keterangan pokok yaitu keadaan penerimaan dan pengeluaran selama jangka waktu tertentu, sedangkan pendapatan merupakan selisih nilai hasil yang diperoleh dari hasil pertanian dengan nilai korbanan.

Pendapatan petani yaitu selisih penerimaan yang didapatkan dengan total biaya yang digunakan dalam usahatani. Pendapatan usahatani diperoleh apabila semua biaya yang telah dikeluarkan dapat ditutupi oleh hasil penjualan dari kegiatan produksi yang telah dilakukan. Menurut Suratiyah, (2006:18) faktor-faktor yang mempengaruhi pendapatan adalah: (1) Faktor internal yaitu: umur petani, pendidikan, jumlah tenaga kerja keluarga, luas lahan, dan modal; (2) Faktor eksternal yaitu: input meliputi ketersediaan dan harga, output meliputi permintaan dan harga; (3) Faktor manajemen.

Analisis pendapatan mempunyai dua tujuan bersama yaitu menggambarkan keadaan sekarang dari suatu kejadian usaha dan menggambarkan keadaan yang akan datang dari suatu perencanaan atau tindakan. Boy dan Hotniar (2009:3), Pendapatan menunjukan jumlah seluruh uang yang diterima oleh Tabel. 2. Jumlah Populasi Sampel

\begin{tabular}{|c|l|c|c|}
\multirow{2}{*}{ No. } & \multicolumn{1}{|c|}{ Desa Sampel } & \multicolumn{2}{|c|}{ Jumlah Petani Alih Fungsi Lahan (Orang) } \\
\cline { 2 - 4 } & \multicolumn{1}{|c|}{ Populasi } & Sampel \\
\hline 1 & S. Kuruk I & 32 & 16 \\
2 & S. Kuruk II & 16 & 8 \\
3 & S. Kuruk III & 20 & 10 \\
\hline \multicolumn{2}{|c|}{ Jumlah } & 68 & 34 \\
\hline
\end{tabular}

Sumber: Kecamatan Seruway, 2018

Variabel dan data yang dianalisis :

1. Luas Lahan Garapan (Ha),

2. Biaya Produksi (Rp/Ha/Tahun),

3. Produksi (Kg/Ha/Tahun),

4. Nilai Produksi (Rp/ Ha/Tahun,

5. Pendapatan $(\mathrm{Rp} / \mathrm{Ha} / \mathrm{Tahun})$.

\section{Metode Analisis Data}

Data yang diperoleh dari lapangan baik data primer maupun data sekunder kemudian diolah dengan cara mentabulasikan kedalam bentuk tabelaris sesuai dengan kebutuhan analisis. seseorang atau rumah tangga selama jangka waktu tertentu, pendapatan terdiri dari upah, atau penerimaan tenaga kerja, pendapatan dari kekayaan seperti: (sewa, bunga dan deviden) serta pembayaran transfer atau penerimaan dari pemerintah seperti tunjangan sosial atau asuransi pengangguran.

Pendapatan bersih (keuntungan) adalah selisih antara total penerimaan (TR) dan total biaya (TC). Tujuan ini dapat diformulasikan sebagai berikut : $\pi=\mathrm{pq}-\mathrm{c}(\mathrm{q})$. Keuntungan juga merupakan insentif bagi produsen untuk melakukan proses produksi. Keuntungan inilah yang mengarahkan produsen untuk mengalokasikan sumber daya ke proses produksi tertentu. Produsen bertujuan untuk memaksimumkan keuntungan dengan kendala yang dihadapi (Sunaryo, 2001:8).

\section{METODE PENELITIAN}

Metode penelitian yang digunakan dalam penelitian ini adalah metode survey. Lokasi penelitian yaitu Kecamatan Seruway Kabupaten Aceh Tamiang. Objek dalam penelitian ini hanya dibatasi pada petani yang melakukan kegiatan alih fungsi lahan perkebunan sawit ke jeruk manis yang ada dalam wilayah kecamatan Seruway Kabupaten Aceh Tamiang. Ruang lingkup penelitian ini meliputi luas lahan garapan, penggunaan tenaga kerja, biaya produksi, produksi dan pendapatan.
Hipotesis yang telah diajukan, dianalisis dengan menggunakan statistik uji Chi Square dengan rumus sebagai berikut :

$X^{2}=\sum_{i=1}^{B}\left[\frac{O i j-E i j}{E i j}\right]^{2} \ldots . . .($ Sudjana,

2005:273)

Dimana :

$X^{2}:$ Chi Square

Oij : Frekwensi yang diamati

Eij : $\quad$ Frekwensi yang diharapkan

Kriteria pengambilan keputusan : 
$\mathrm{H}_{\mathrm{a}}$ : Terdapat perbedaan pendapatan petani sebelum dan sesudah alih fungsi lahan kelapa sawit ke jeruk manis di Kecamatan Seruway Kab. Aceh Tamiang.

$\mathrm{H}_{0}$ : Tidak terdapat perbedaan pendapatan petani sebelum dan sesudah alih fungsi lahan kelapa sawit ke jeruk manis di
Kec. Seruway Kab. Aceh Tamiang. Kaidah pengambilan keputusan sebagai berikut : - Jika $X^{2}$ hitung > t tabel maka terima $\mathrm{H}_{\mathrm{a}}$ tolak $\mathrm{H}_{0}$.

- Jika $X^{2}$ hitung $\leq \mathrm{t}$ tabel maka terima $\mathrm{H}_{0}$ tolak $\mathrm{H}_{\mathrm{a}}$.

\section{HASIL DAN PEMBAHASAN}

Karakteristik Responden

Tabel 3. Karakteristik Responden di Kecamatan Seruway Kabupaten Aceh Tamiang, 2017

\begin{tabular}{|c|l|c|c|c|c|}
\hline No & $\begin{array}{c}\text { Desa } \\
\text { Sampel }\end{array}$ & $\begin{array}{c}\text { Umur } \\
\text { (Tahun) }\end{array}$ & $\begin{array}{c}\text { Pendidikan } \\
\text { (Tahun) }\end{array}$ & $\begin{array}{c}\text { Pengalaman } \\
\text { (Tahun) }\end{array}$ & $\begin{array}{c}\text { Tanggungan } \\
\text { (Orang) }\end{array}$ \\
\hline 1. & S. Kuruk I & 39,94 & 9.75 & 2,88 & 3 \\
2. & S. Kuruk II & 37,10 & 10,13 & 3,00 & 3 \\
3. & S. Kuruk III & 39,60 & 8,40 & 2,55 & 3 \\
\hline \multicolumn{2}{|r|}{ Rata-rata } & 39,26 & 9,44 & 2,81 & 3 \\
\hline
\end{tabular}

Sumber: Data primer diolah (2018)

Tanggapan petani tentang alih fungsi lahan dikatagorikan kedalam 3 alternatif jawaban perkebunan kelapa sawit ke jeruk manis di yaitu tidak setuju, setuju dan sangat setuju yang Kecamatan Seruway Kabupaten Aceh Tamiang masing-masing diskor dengan skala 1,2,3.

\section{Hasil Kuisioner Tentang Alih Fungsi Lahan Perkebunan}

Tabel 4. Hasil Tanggapan Petani Tentang Alih Fungsi Lahan Perkebunan di Kecamatan Seruway Kabupaten Aceh Tamiang, 2017

\begin{tabular}{|c|l|c|}
\hline No & \multicolumn{1}{|c|}{ Pernyataan } & Rerata Skor \\
\hline 1 & $\begin{array}{l}\text { Beralih fungsi lahan kebun ke jeruk manis dilakukan petani karena } \\
\text { faktor sosial ekonomi }\end{array}$ & 2,1 \\
\hline 2 & $\begin{array}{l}\text { Pengalaman petani berpengaruh terhadap petani dalam melakukan } \\
\text { alih fungsi lahan }\end{array}$ & 2,1 \\
\hline 3 & $\begin{array}{l}\text { Tingkat pendidikan petani berpengaruh terhadap petani dalam } \\
\text { melakukan alih fungsi lahan }\end{array}$ & 2,0 \\
\hline 4 & $\begin{array}{l}\text { Tinggi rendahnya pendapatan petani berpengaruh terhadap petani } \\
\text { dalam melakukan alih fungsi lahan }\end{array}$ & 2,1 \\
\hline 5 & $\begin{array}{l}\text { Petani melakukan alih fungsi lahan karena sempitnya lahan kebun } \\
\text { yang tersedia }\end{array}$ & 2,2 \\
\hline 6 & $\begin{array}{l}\text { Petani beralih lahan perkebunan kelapa sawit ke perkebunan jeruk } \\
\text { manis karena program pemerintah }\end{array}$ \\
\hline
\end{tabular}

Sumber: Data primer diolah (2018)

\section{Penggunaan Tenaga Kerja}

Penggunaan tenaga kerja pada usahatani kelapa sawit di kecamatan Seruway yaitu tenaga kerja dalam keluarga (DK) sebesar 35,79HKP dan tenaga kerja Luar Keluarga (LK) sebesar 26,08HKP, dengan total penggunaan tenaga kerja per usahatani adalah 61,87 HKP. Penggunaan tenaga kerja pada usahatani jeruk manis di kecamatan Seruway hanya menggunakan tenaga kerja dalam keluarga (DK) dengan total penggunaan tenaga kerja yaitu sebesar 30,05 HKP. Adapun tenaga kerja
Luar Keluarga (LK) bernilai 0 karena jenis kegiatan pengelolaan yang dilakukan pada usahatani jeruk manis tidak banyak membutuhkan tenaga kerja.

\section{Penggunaan Biaya Produksi}

Penggunaan biaya produksi pada usahatani kelapa sawitdi Kecamatan Seruwaysebesar Rp.7.083.514per usahatani dan Rp.18.441.229per hektar. Penggunaan biaya produksi pada jeruk manisdi Kecamatan Seruway sebesar Rp. 2.904.427 per usahatani 
dan Rp. 13.401.607per hektar.

\section{Pendapatan Petani}

Tabel 5. Rata-rata Pendapatan Petani Sebelum dan Setelah Melakukan Alih Fungsi Lahan di Kecamatan Seruway Kabupaten Aceh Tamiang, 2017

\begin{tabular}{|c|c|c|c|}
\hline \multirow{2}{*}{ No } & Desa & \multicolumn{2}{|c|}{ Pendapatan $(\mathrm{Rp} / \mathrm{Ha} / \mathrm{Thn})$} \\
\cline { 3 - 4 } & Sampel & Kelapa sawit & Jeruk manis \\
\hline 1. & Sungai Kuruk I & 22.070 .504 & 20.109 .348 \\
2. & Sungai Kuruk II & 20.644 .785 & 19.863 .881 \\
3. & Sungai Kuruk III & 20.583 .099 & 18.047 .671 \\
\hline \multicolumn{2}{|c|}{ Rata-rata } & 21.329 .328 & 19.445 .216 \\
\hline
\end{tabular}

Sumber: Data primer diolah (2018)

Tabel 6. Rata-rata Pendapatan Petani Sebelum dan Setelah Melakukan Alih Fungsi Lahan di Kecamatan Seruway Kabupaten Aceh Tamiang, 2017

\begin{tabular}{|c|c|c|c|}
\hline \multirow{2}{*}{ No } & Desa & \multicolumn{2}{|c|}{ Pendapatan (Rp/Ha/Thn) } \\
\cline { 2 - 4 } & Sampel & Kelapa sawit & Jeruk manis \\
\hline 1. & Sungai Kuruk I & 22.070 .504 & 20.109 .348 \\
2. & Sungai Kuruk II & 20.644 .785 & 19.863 .881 \\
3. & Sungai Kuruk III & 20.583 .099 & 18.047 .671 \\
\hline \multicolumn{2}{|c|}{ Rata-rata } & 21.329 .328 & 19.445 .216 \\
\hline
\end{tabular}

Sumber: Data primer diolah (2018)

Tabel 5. Rata-rata Pendapatan Petani Sebelum dan Setelah Melakukan Alih Fungsi Lahan Kecamatan Seruway Kabupaten Aceh Tamiang, 2017

\begin{tabular}{|c|l|r|r|}
\hline \multirow{2}{*}{ No } & \multicolumn{1}{|c|}{ Desa } & \multicolumn{2}{|c|}{ Pendapatan $(\mathrm{Rp} / \mathrm{Ha} / \mathrm{Thn})$} \\
\cline { 3 - 4 } & \multicolumn{1}{|c|}{ Sampel } & Kelapa sawit & Jeruk manis \\
\hline 1. & Sungai Kuruk I & 22.070 .504 & 20.109 .348 \\
2. & Sungai Kuruk II & 20.644 .785 & 19.863 .881 \\
3. & Sungai Kuruk III & 20.583 .099 & 18.047 .671 \\
\hline \multicolumn{2}{|c|}{ Rata-rata } & 21.329 .328 & 19.445 .216 \\
\hline
\end{tabular}

Sumber: Data primer diolah (2018)

\section{Analisis Chi-Square}

Berdasarkan hasil perhitungandiperoleh nilai $\mathrm{X}^{2}$ hitung sebagaimana tabel berikut:

Tabel 6. Analisis Chi-Square

\begin{tabular}{|c|c|c|c|}
\hline \multirow{2}{*}{$\mathrm{X}^{2}$ hitung } & \multicolumn{2}{|c|}{$\mathrm{X}^{2}$ tabel } & Kesimpulan \\
\cline { 2 - 3 } & $\alpha=0,05$ & $\mathrm{Db}$ & \\
\hline 9,95 & 9,488 & 4 & $\mathrm{X}^{2}$ hitung $>\mathrm{X}^{2}$ tabel \\
\hline
\end{tabular}

Sumber: Data primer diolah (2018)

Hal ini menunjukkan bahwa $\mathrm{X}^{2}$ hitung $>\mathrm{X}^{2}$ tabel. Dapat dilihat bahwa perbandingan antara nilai $\mathrm{X}^{2}$ hitung sangat berbeda dengan nilai $\mathrm{X}^{2}$ tabel. Dengan demikian dapat dinyatakan bahwa terdapat pengaruh pendapatan petani yang signifikan akibatalih fungsi lahan perkebunan kelapa sawit ke jeruk manis di Kecamatan Seruway Kabupaten Aceh Tamiang. Jadi Hipotesis yang meenyatakan alih fungsi lahan perkebunan berdampak terhadap pendapatan petani di Kecamatan Seruway Kabupaten Aceh Taming diterima (terima Ha tolak Ho)

\section{Kesimpulan :}

1. Pendapatan yang diperoleh sebelum dan setelah melakukan alih fungsi lahan di kecamatan Seruway pada perhitungan di atas maka pendapatan petani sebelum melakukan alih fungsi lahan yaitu usahatani kelapa sawit Rp. 21.329.328per hektar

2. Pendapatan menurun setelah melakukan alih fungsi lahan ke 
jeruk manis yaitu sebesar Rp. 19.445.216per hektar.

3. Terdapat pengaruh pendapatan petani yang signifikan akibatalih fungsi lahan perkebunan kelapa sawit ke jeruk manis di Kecamatan Seruway Kabupaten Aceh Tamiang.

\section{Saran}

Disarankan kepada petani untuk terus meningkatkan pengetahuan dalam usahatani jeruk manis khususnya agar dapat meningkatkan produksi usahataninya, sehingga dapat meningkatkan hasil produksi yang berlebih dapat dipasarkan sehingga bisa menambah pendapatan keluarga

\section{DAFTAR PUSTAKA}

Dinas Pertanian Kabupaten Kabupaten Aceh Tamiang. 2012 Tingkat Perubahan Lahan Pertanian. Dinas Pertanian Kabupaten Aceh Tamiang.

Fauzi, Yan. Dkk. 2012. Kelapa Sawit : Budidaya, Pemanfaatan Hasil dan Limbah, Analisis Usaha dan Pemasaran. Jakarta : Penebar Swadaya.

Gustiyana, H.2003. Analisis Pendapatan Usahatani untuk Produk Pertanian. Selemba Empat. Jakarta.

Hernanto. 2000. Ilmu Usaha Tani. Penebar Swadaya. Jakarta

Ilham, dkk, 2005. Perkembangan dan FaktorFaktor Yang Mempengaruhi Konversi Lahan Sertan Dampak Ekonominya. IPB Press. Bogor.

Isa, I. 2006. Strategi Pengendalian Alih Fungsi Tanah Pertanian. Bogor

Kustiwan, Iwan. 2007. Kajian permasalahan dan Kebijaksanaan Pengendalian Konversi Lahan Pertanian. Wilayah Pantai Utara Pulau Jawa. Jurnal Ilmiah. Yogyakarta

Liliweri, A. 2007. Dasar-Dasar Komunikasi Antar Budaya. Yogyakarta. Pustaka Pelajar.

Mosher. 2007. Menggerakan dan Membangun Pertanian. Yasa Guna. Jakarta.
Mubyarto, 1996. Pengantar Ekonomi Pertanian, LP3ES, Jakarta.

Mubyarto, 2002. Pengantar Ekonomi Pertanian, LP3ES, Jakarta.

Nazir, M. 2005.Metode Penelitian. Jakarta : Ghalia Indonesia.

Nazir, M. 2009.Metode Penelitian. Jakarta : Ghalia Indonesia.

Pahan Iyung. 2006. PanduanLengkap Kelapa Sawit: Manajemen Agribisnis Hulu

Hingga Hilir. Jakarta: Penebar Swadaya

Partadiredja. 1997. Pengantar Ekonomi. BPFE. Yogyakarta,

Reksohadiprojo, Sukanto. 1988. Organisasi Perusahaan. Jakarta: Karunika UT

Rustiadi. 2006. Pengelolaan Perkebunan dan Lahan Pertanian.Jakarta: Rajagrafindo Persada

Setyamidjaja, D. 2003. Bididaya Jeruk Manis. IPB Press. Bogor

Soekartawi,1994. Teori Ekonomi Produksi dengan pokok Bahasan analisis Fungsi Cobb- Douglas, Rajawali Pers, Jakarta.

Sudarmo, S. 1989. Pengendalian Hama dan Penyakit Perkebunan. Kanisius : Yogyakarta.

Sudjana.2005. BukuPenelitian Dan Penilaian. Bandung: SinarBaru

Sugiyono.

2008.MetodePenelitianKuantitatifK ualitatif $R$ dan $D$. Bandung: Alfabeta

Suratiyah, Ken. 2006. Ilmu Usahatani. Penebar Swadaya. Jakarta.

Syarifuddin, 2009. Pengaruh Penyelenggaraan Penyuluhan Pertanian Melalui Integrasi Dinamis Antara Penyuluh Pertanian dan Petani. Jurnal Pasca Sarjana Pengelolaan Sumberdaya Alam dan Lingkungan.

T. Sunaryo. 2001. Ekonomi Manajerial Aplikasi Teori Ekonomi Mikro. Jakarta. Erlangga

Wiratha. 2006. Metode Penelitian Sosial Ekonomi. Andi. Yogyakarta 